\section{News analysis}

\section{INDIA: GUTKA PLASTIC PACK BAN}

One of the most interesting developments in India recently has been the temporary banning last December of the sale of gutka, ground tobacco and flavourings sold in pouches, sucked by millions of Indians and known to cause cancer and other serious diseases (see India: advocates hit back at smokeless industry. Tob Control 2007;16:165-6; Gupta PC. Gutka: a major new tobacco hazard in India. Tob Control 1999;8:132). Even though the ban was made by the Supreme Court of India, with venerable judges intoning strident condemnation of government and society for not protecting India's youth from the product, it may not be the ban itself that is of most importance-and most potential for public health advocates in other countries-but the case that led to it. This was a case brought under a law designed to protect, not children, nor health, but the environment.

Gutka smokeless tobacco is banned from sale in India from March 2011 because its plastic packaging is harmful to the environment. The case was brought under the country's Plastic Management and Disposal Rules, 2009. Indian health advocates reckon that colleagues around the world can help make life difficult for ambitious Indian tobacco companies with an eye on increased gutka exports, such as those to the large south Asian populations of Europe. In addition, they suggest, other countries' environmental protection laws may provide opportunities for similar action to be taken, based on, for example, pollution caused by dumping billions of tobacco packs in landfill sites every year.

Whatever the roots of the decision, the utterances of some of India's most senior judges provided stirring copy for news media. Hearing that gutka manufacturers claimed a ban would cause the whole industry to come to a standstill, one judge,

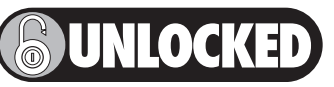

This paper is freely available online under the BMJ Journals unlocked scheme, see http://tobaccocontrol. bmj.com/site/about/unlocked.xhtml

All articles written by David Simpson unless otherwise attributed. Ideas and items for News Analysis should be sent to: David.Simpson@ctsu.ox.ac.uk
Justice Ganguly, said, "Let it come." He told the manufacturers to switch to non-plastic packaging even if it put up the price. "Let gutka become costlier," he said; "The public would benefit." He also concluded that the government was "...privy to gutka addiction... These are powerful lobbies... The youth of today is imperilled by the government's lack of concern for public health. In some States, where economic prosperity has taken place, young people have been compromised... Those who govern have to be alive to this problem. It is their duty to see that youth get all conditions for fulfilment. Where is the protest in the student community? Where is the idealism? Even in Bengal, where student movements have been vibrant, there is silence."

It must be said that compared to just 20 years ago, there is in fact a great deal of idealism now in India about reducing diseases caused by tobacco, including among students. Colleagues there are thinking not just about the next moves at home, but how the world at large might benefit from the Indian precedent, by considering new types of action in the fight against tobacco.

\section{SWITZERLAND: BAD BOY OF EUROPE SHOWS NO SIGN OF REFORM}

What can be done about Switzerland? Geographically at the heart of Europe, but not a member of the European Union $(E U)$, its public health policy on tobacco is a fossilised example of industry selfregulation. This naive approach used to be popular around the world, especially with tobacco companies, as it shielded them from effective action. Lazy or naive governments could be seen to be doing something, while not upsetting big business.

The system relies on 'gentlemen's agreements' between the tobacco industry and the government. The former pledges to abide by codes of conduct covering areas such as promotion, labelling and toxicity, while the latter's reciprocal pledge is to take no further action for an agreed number of years. Its worst absurdities were arguably demonstrated in the UK during the 1970s and 1980s. To say that tobacco companies have always run rings round governments in negotiating self-regulation agreements, knowing they can easily circumvent any new regulations to which they 'submit', is only to hint at how ineffective, inappropriate and even counter-productive such a system was and always will be for regulating an addictive product that kills half its lifetime users (see Wander N, Malone RE. Making big tobacco give in: you lose, they win. Am J Public Health 2006;96:2048-54).

Tobacco promotion of many types is still widespread in Switzerland. At the federal level, regular tobacco advertising is only banned on television. Whereas in some cantons (the 26 states that make up federal Switzerland) outdoor billboard tobacco advertising is banned, in the others it is still permitted, as it isnationwide-in the printed press, in cinemas, in car parks, and on the internet. Most notorious, though, is tobacco sponsorship of sport and musical events, still permitted and offering an easy way of getting round the TV ad ban, as was the case of the Davidoff Swiss Indoors tennis tournament, terminated only because of external, not national constraints (see Switzerland: health beats Davidoff. Tob Control 2010;19:5-6). In addition, the country has some 17000 cigarette vending machines, which in recent years have been steadily transformed into advertisements. Point of sale advertising is also unregulated, with large screens showing animated cigarette ads now commonplace in shops selling tobacco and also in vehicle fuel stations.

There are a few bright spots, such as graphic health warnings, which cover 55 per cent of the back of cigarette packs; a dedicated 'health tax' on every cigarette pack yields more than 15 million Swiss Francs (US\$15.5 million) for tobacco control; and some creative health promotion: the federal office of public health recently launched a high-spend national campaign promoting an imaginary toxicfree cigarette (mimicking ads for Kent cigarettes), the 'smoke-free cigarette', showing an empty cigarette pack. Also, there is no lack of dedication and hard work by people working in many organisations, including government, who want to do the right thing, but who are constrained by the politicians, who seem set on putting tobacco interests first.

So Switzerland, whose name is synonymous with excellence in so many areas of life, nevertheless finds itself widely viewed as a disgrace within the international public health community for its failure to address its leading cause of disease, disability and premature death at home, and its far from internationally publicspirited behaviour in other areas of regulation. For example, the current standards for maximum tar, nicotine and carbon monoxide cigarette emission levels are modeled on EU regulations, but the industry has lobbied-successfully, so 


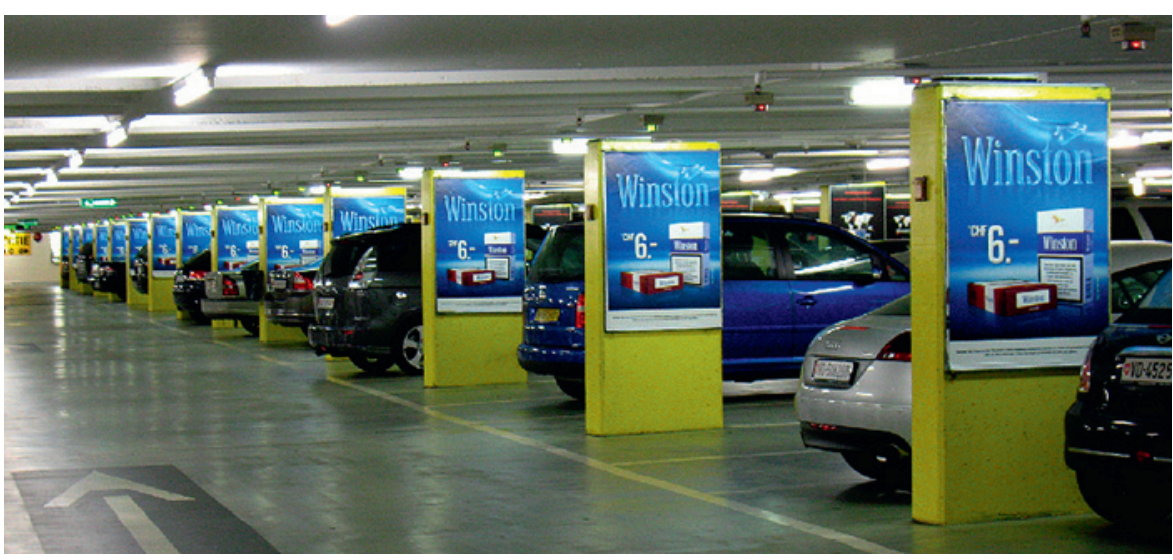

Switzerland: cigarette ads in a Geneva underground car park.

far-to ensure that Switzerland does not fully adopt the European regulations. These should apply to all cigarettes manufactured in Europe, whether consumed in the region or exported, but Philip Morris, British American Tobacco and Japan Tobacco International have repeatedly threatened to relocate their Swiss factories abroad unless they can continue to make cigarettes with unlimited tar and nicotine content for export to Asian, African and former Soviet bloc countries. Currently, Switzerland is in a new round of bilateral negotiations with the EU and this issue is among the most contentious under discussion, with high pressure lobbying involving a sizeable group of tobacco-friendly members of parliament.

Public health advocates find it odd that Switzerland hosts the international headquarters of the WHO, but has still not ratified the Framework Convention on Tobacco Control (FCTC), which it signed in 2004. True, the government tobacco control programme for 2008-2012 includes ratification as an objective, but so far, action to implement this has been notable only for its absence. Even if it really does intend to ratify, it is unlikely to do it before 2013. Moreover, last November the government indicated its opposition to a popular initiative launched by the Swiss Lung League, which collected 133000 signatures to call a constitutional referendum to ban smoking in public indoor places and at the workplace. Even though that proposal would be less than a total workplace ban-it would permit dedicated smoking rooms without service (like the French model)-the federal government thought even this much would go too far. It will recommend citizens to vote against it, without putting forward a counter-proposal.
The current federal law is similar to the recently repealed 'Spanish model' (see Spain: beyond the 'Spanish model' to a total ban. Tob Control 2010;20:6-7). It allows small establishments to declare themselves smoking places and larger establishments to have large rooms where smoking is permitted. One extraordinarily and shameful feature of the federal law is that people can be recruited to work in establishments where smoking is permitted if they accept a clause in their employment contracts acknowledging that they will be exposed to tobacco smoke, prompting speculation about how other workers exposed to toxins at work, say in the removal of asbestos insulation in buildings, would feel about having to waive their rights to protection. Such outrageous practice is, needless to say, one of several ways in which the federal law is not compliant with the FCTC's standards. This, together with the likely outcome of political changes in elections towards the end of this year, make health advocates pessimistic that Switzerland's declared intention to ratify the FCTC will be fulfilled in the foreseeable future.

\section{WORLD: HARD WORK WINS HEALTH GAINS AT CoP4}

The Conference of the Parties (CoP), the governing body of the WHO Framework Convention on Tobacco Control (FCTC), held its fourth session-CoP4'-in Montevideo, capital of Uruguay, last November The third session, CoP3, had achieved better results for health than many had forecast (see World: health triumphs at CoP3. Tob Control 2009;18:6-7); and CoP4 also saw major achievements for health, despite unprecedented efforts by the tobacco industry to block progress.

Among the main topics addressed by the 172 FCTC Parties at CoP4 were flavourings and additives (covered by Articles 9 and 10), which had been the focus of a long, global tobacco industry propaganda campaign during the months leading up to the Montevideo meeting. The industry tried to portray the guidelines as a ban on certain types of tobacco that would hurt millions of farmers, particularly in developing countries. However, CoP4 delegates, with support from many grower countries, endorsed the guidelines' aim of limiting flavourings, which are used to lure new young smokers.

The meeting also agreed to set up a working group to draft guidelines on tobacco taxation, the single most effective short-term measure to reduce consumption. Despite much evidence of their dual benefits of increased revenue for governments and reduced disease rates following lower consumption, tax rises are often blocked by finance ministries influenced by industry lobbying, which fail to appreciate what is in their countries' best interests.

Other guidelines adopted by CoP4 included those on Article 12 (education, communication, training and public awareness), and Article 14 (cessation policy), both of which passed without difficulty. The mandate of the working group dealing with Articles 17 and 18, on policy options and recommendations for economically viable alternatives to tobacco, particularly for growers, was extended.

A decision was adopted to support Parties being attacked under trade and investment agreements for measures implementing the FCTC and its guidelines-in particular the host country, Uruguay, whose labelling and packaging requirements are under legal attack by Philip Morris.

It was also agreed to press for linking FCTC implementation to international development efforts, including the 2011 United Nations summit on non-communicable diseases. Negotiations on the Illicit Trade Protocol will continue until 2012, with an informal working group addressing unresolved issues from the last formal negotiating session (held in March 2010), as well as how the protocol will be financed and how it can best complement other agreements (eg, the UN Convention on Transnational Organized Crime).

So which countries backed or opposed which Articles? Sources close to the proceedings said that on Articles 9 and 10, Zimbabwe, Malawi and Zambia, with backing from some other African countries, repeatedly brought up the supposed 


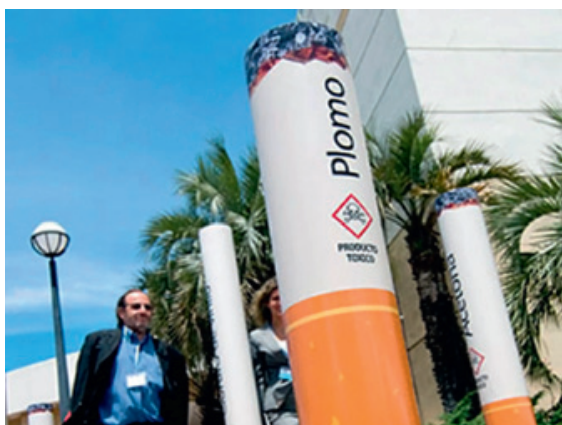

World: the Uruguayan health minister, Daniel Olesker, makes his way to the CoP4 meeting though an installation of large model cigarettes. Photo: Andrew Kerr.

impact on burley tobacco growers. Not being FCTC Parties, Zimbabwe and Malawi had to wait until the end of each section before commenting. Within the AFRO region, however, those working for the adoption of the guidelines eventually won out. China, sometimes with Japan, criticised the concept of 'attractiveness' for being too vague and wanted postponement until solid proposals on addictiveness and toxicity were produced. China, reputedly most concerned about the Chinese tobacco monopoly, took procedures to extreme limits until eventually a face-saving compromise persuaded its delegates to agree a consensus position.

The European Union, at first opposing the creation of an Article 6 (taxation) working group, reversed its position after an overnight adjournment. It also opposed the allocation of any budget for holding working group meetings, but India, Brazil and others fought for a footnote to be added to the document of decisions, for targeted donations to be allowed to fund such activities. The report to the plenary session omitted the hard-won footnote, but an impassioned plea from South Africa (which had proved such a healthfriendly host of CoP3), supported by Brazil and India, finally saw it inserted.

CoP4 achieved good outcomes for health due to the perseverance of many in official government delegations and those observing and advising from the nongovernmental sector. It is not surprising that for all the hard work necessary in the past, the present and no doubt also in the future, the FCTC remains the envy of colleagues working in other areas of public health.

\section{CANADA: NEW WARNINGS PROPOSED}

It took a decade to get back on track, but Canada now appears set to once again offer some of the biggest and possibly best cigarette warning labels in the world. They will cover 75 per cent of the pack-only Uruguay's are larger, at 80 per cent, though Honduras is set to match that standard. In addition, the new Canadian warnings will feature a quit-smoking hotline number and social media links to target younger smokers.

It was in June 2000 that Canada's parliament unanimously approved world precedent-setting colour warning labels, formally introduced in 2001, that covered $50 \%$ of the front and back panels of cigarette packs. In the intervening decade, dozens of other countries have developed and sometimes renewed their own warning labels, often larger and far more graphic than Canada's original set of 16 images.

After more than six years of study and focus groups costing a reported $\mathrm{C} \$ 3.6$ million (US\$3.63 million), new warnings appeared to be at hand, only for Canadians to learn in September 2010 that the conservative government had shelved the warnings in order to focus on anti-smuggling efforts. The media's editorial outcry was swift and strong, led by the Canadian Medical Association Journal and several newspapers, all asking the same basic question: Why not do both?

In late December, however, with most people on holiday, and after news reports had revealed extensive lobbying of the government by the tobacco industry around the time the warning were shelved, the government did an about-turn and declared that the warnings were set to appear after all. No date has yet been given for the introduction of legislation to implement the warnings, and there will be a 75-day period for comment after gazetting of the legislation, but Health Minister Leona Aglukkaq has made a commitment to introduce the warnings some time in 2011.

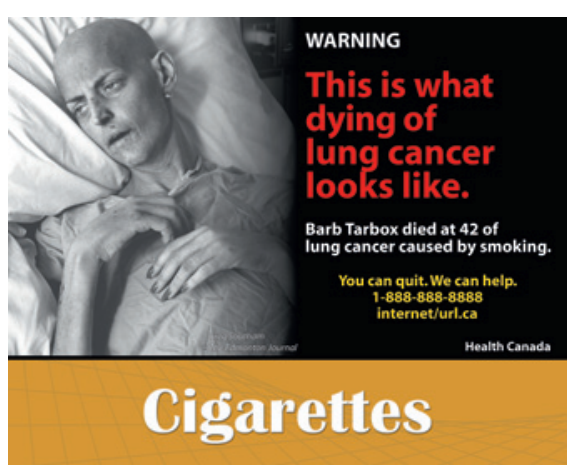

Canada: one of the government's proposed new health warnings, showing the former model Barb Tarbox as she lay dying from lung cancer (photo: Greg Southam, (c) The Edmonton Journal).
At the introductory press conference, only four of the 16 new labels were revealed. Three of them were relatively weak, but a deathbed photo of Barb Tarbox-an image also under consideration for the United States' first colour warning labels-will undoubtedly prove potent, moving, and even disturbing. A former model who campaigned indefatigably to bring an anti-smoking message to students across Canada after her own lung cancer diagnosis, Tarbox will be the face of the new warnings as Canada may yet reclaim leadership in a field it pioneered.

STAN SHATENSTEIN

\section{WORLD: TOBACCO STOCKS DOWNGRADED}

Extraordinary news from the world of international high finance! On 7 January, Citigroup, one of the world's largest and most respected sources of information about financial markets, gave public health advocates worldwide just about the best news they could possibly have to start off the new year. It downgraded its advice to investors on tobacco stocks.

The 60-page report, published on 7 January, also predicted that smoking could disappear in the next 30 to 50 years in developed countries. Under the heading, 'Tobacco: What If the Last Smoker Quits in 2050?', CitiGroup said it was downgrading major tobacco companies' stocks, including British American Tobacco and Philip Morris, as short-term trends had "worsened", and, "... we're also increasingly concerned about the very long term." Since lower profits, the concern of CitiGroup and big investors, tend to mean lower sales, which in turn mean lower rates of disease and premature death in the future, the downgrading of CitiGroup's ratings for tobacco translates as grounds for significant reassurance and optimism for world health.

Under the bold statement, 'Plain packaging is coming', CitiGroup said it expected the European Commission to recommend that generic packaging be considered for Europe; and that Australia would publish its law on generic packaging. It also drew attention to Canada's announcement that health warnings there will need to cover $75 \%$ of the pack, so that packs would look generic there, too. Taking the very long view, it said, it was hard to ignore 50 years of data showing smoking rates falling "in a series of straight lines." If this continued, as it had for 50 years, it meant that the percentage declines in volumes would gradually accelerate, which seemed to be what had been happening. 
Publication of the CitiGroup report led tobacco company shares to show significant reductions in value on the British stock market, an indicator of how seriously CitiGroup's forecasts are taken by investors.

\section{THAILAND: TOUGH NEW REGULATIONS}

The government has announced that it will amend the 1992 Tobacco Products Act and prohibit the sale of tobacco products to people under 20 years old. It will also ban the addition of flavours or vitamins to cigarettes, a move clearly aimed at trying to stop tobacco companies recruiting more young smokers, following exposure of the apparent increase in the use of such additives.

In addition, the government will issue a regulation to ensure that only fire-safer cigarettes are sold in Thailand, becoming the first Asian country to enforce such a measure. The United States pioneered this policy, followed by Canada, Australia and Finland. The European Union is also expected to implement similar measures.

\section{ROMANIA: JTI LETS SLIP THE DOGS OF WAR ON SMUGGLING}

Among the more bizarre examples of the big tobacco companies' attempts to demonstrate that tobacco smuggling is any country's worst enemy, thereby obtaining, they hope, a moratorium on further tobacco tax rises, has been a recent campaign in Romania. Japan Tobacco International (JTI) is spending 300000 euros (US $\$ 404600$ ) on a project to donate 30 sniffer dogs and 30 special cars to Romania's national customs authority. The project will last three years, and will include the training of the dogs and their handlers at 3-month courses.

A spokesperson from the customs service was reported as claiming that a canine team could have a 99 per cent success rate for finding smuggled cigarettes. The customs service already has 10 tobacco dog teams and 30 trained to find illegal drugs. JTI's propaganda about the donation included glowing statistics about cigarette companies' 'contributions' to state finances, but did not mention the sums it spent trying to convince governments that it should not 'contribute' so much.

It is not known whether, in the bad old days when tobacco companies colluded with organised black market activities, trained anti-tobacco dogs ever turned round and bit their industry sponsors.

\section{WORLD: NEW HEART HEALTH FILM}

Aiming to raise public awareness of the links between cardiovascular disease and secondhand smoke, the Global Smokefree Partnership (GSP) has produced a new film and educational leaflet summarising the scientific evidence on the cardiovascular effects of secondhand smoke and its implications for cardiologists. Through GSP, over 15 organisations collaborated to design, produce and distribute the film and leaflet. Resource production was led by the US Centers for Disease Prevention and Control (CDC), Roswell Park Cancer Institute, the World Heart Federation and the World Lung Federation. English and Chinese language versions of the resource were launched last June at the World Congress of Cardiology (WCC) in Beijing, China.

Entitled Warning: Secondhand Smoke is Hazardous to Your Heart, the film and leaflet are available free in English, Chinese and Spanish at http://globalsmokefree partnership.org/heart/data/index.html.

\section{UK: NOVEL CESSATION AID FOR MUSLIMS}

Although the second Wednesday of March, designated No Smoking Day, has long has been the focus for tobacco cessation activities in the United Kingdom, health professionals recognise that there are better opportunities for some people to stop smoking. As most Britons would admit, the traditional time to make resolutions about personal behaviour, New Year, is far from suitable for breaking an addiction. Many smokers shivering out another cold, wet British winter, their money spent on seasonal holiday celebrations and presents, not to mention the effects of eating and drinking more than they should and a return to work looming, find it is hardly the best time to approach something that may cause at east temporary discomfort. Hence No Smoking Day is timed to capitalise on the more optimistic feelings that come when spring is in the air. However, in some traditions there may be an even better season for cessation.

This thought occurred to health workers in Leicester, a city in the east midlands of England with a substantial ethnic minority population, including many Muslims of south Asian origin. In 2007-2008, 14 per cent of all users of STOP!, Leicester's specialist stop smoking service, were from a minority ethnic background; and after a comprehensive programme over the following year, the proportion being treated for smoking rose to $21 \%$, with the bonus of sustainable, productive partnerships being forges with Leicester's Muslim communities.

Perhaps the most striking aspect of the campaign was a highly distinctive cessation initiative built around the Islamic holy month of Ramadan, which in 2009 began at the end of August. During Ramadan, Muslims must refrain from all food, drink, cigarettes and any kind of tobacco from dawn to sunset. This provided the ideal opportunity to experience being smokefree. In addition, health workers came up with a something unique: they promoted use of a dental tooth stick called a 'siwaak', a wooden brush from the native arak tree that grows in Egypt, which has high cultural and spiritual significance within the Islamic tradition. Its use was encouraged to reduce the impact of cravings and ease the void left by the smoker's repetitive hand to mouth action. Key to this was the assurance that siwaak use would not invalidate a person's fasting, unlike smoking in daylight.

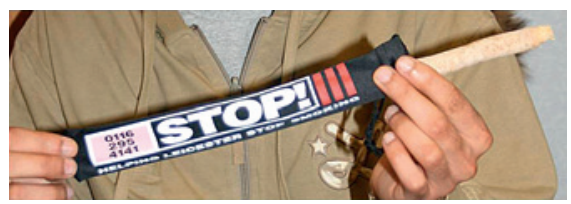

UK: a siwaak, a natural toothbrush from the arak tree of Egypt, with cultural and spiritual significance in the Islamic tradition, as issued to Muslims in Leicester to help them give up smoking in a cessation campaign run during Ramadan, 2010.

Unsurprisingly, uptake of cessation materials, including the siwaak, was excellent and media attention lively. STOP! is currently making plans to run a special cessation campaign targeted at Muslims again this year during Ramadan, which begins on 1 August.

Tobacco Control 2011;20:89-92. doi:10.1136/tc. 2011.043240 